\title{
Financial Impact of Moving to Cloud Computing
}

\author{
Dmitriy V. Chulkov \\ Indiana University Kokomo \\ Steven R. Cox \\ Indiana University Kokomo \\ Joungyeon Kim \\ Indiana University Kokomo
}

This study explores the impact of cloud service adoption on the financial performance of the adopting firms. While the popularity of cloud computing continues to grow, disagreements abound regarding the costs and benefits of its adoption. Cloud service providers claim that the primary benefits are reduced cost and increased profitability due to improved operational efficiency. Paradoxically, accounting and finance professionals warn about potential negative impact on key financial reporting metrics including increased operating expenses and decreased earnings due to the added subscription fees. We analyze a sample of reported early cloud service adopters and compare their financial reporting metrics of interest to those from a control group of firms from the same industries over the period from 2005 to 2015 covering the first wave of large-scale adoption. We find that early adopters exhibit lower depreciation expenses and lower operating expenses than the average firm. Early adopters also exhibit higher market-to-book ratios, implying that investors expect comparably higher earnings growth, potentially due to the expected efficiencies achieved by using cloud computing.

Keywords: cloud services, technology adoption, financial performance

\section{INTRODUCTION}

Cloud computing adoption has become widespread and its benefits are a subject of much discussion in both popular and academic outlets (Fuhrt and Escalante, 2010; Youssef, 2012; Yang et al., 2017; Novais et al., 2019). In cloud computing, service users share applications, platforms, or infrastructure provided and maintained by the cloud service provider. The users are charged subscription fees based on the amount of usage similar to the way utilities services are consumed and billed. This model has rapidly gained popularity among corporate users because of potential for improved reliability while avoiding equipment investment costs as well as the financial commitment of maintaining an in-house information technology (IT) department with the responsibility for developing and maintaining equipment and services. Pay-as-you-go subscription arrangements also make it easier for users to scale the level of computing services in response to their growth in the market (Fuhrt and Escalante, 2010). 
Höfer and Karagiannis (2011) present a taxonomy of cloud computing arrangements and identify a wide variety of forms classified into infrastructure-as-a-service (IaaS), platform-as-a-service (PaaS), or software-as-a-service (SaaS). Cloud service providers claim significant operational benefits of moving to the cloud as it provides scalability, accessibility, and availability of infrastructure and software (Youssef, 2012). The recent surge in demand for big data analytics, artificial intelligence and machine learning forces companies to look to cloud platforms that are more scalable and robust in supporting large and complex data sets and computing power (Yang et al., 2017; Novais et al., 2019). Goasduff (2015) outlines the positive financial aspects of cloud computing including greater cost agility, increased retained cash, and reduced opportunity costs. Operating expenses of businesses can also decrease in other areas because of the reduction in IT staff salaries, rental spaces, associated utility bills, and depreciation expenses of computing machines. There can be indirect savings due to increased operational efficiencies such as reduced travel expenses and overtime wages. Businesses increasingly opt for cloud services in place of on-premise computing to enjoy these benefits.

However, some accounting and finance professionals have greeted cloud computing with mixed feelings (Goasduff, 2015; Conner, 2016; Goldstein, 2020a, 2020b). One concern is the potential negative impact on key financial metrics such as decreased EBITDA and increased operating expenses. These negative effects may exist because of the shift in the accounting treatment of the associated costs from capital expenditures under an on-premise system to operating expenditures under a cloud computing service. In addition, operating expenses may increase due to the subscription fees paid to the cloud service providers. Goasduff (2015) reports that cloud computing investment often receives pushback from CFOs due to the negative impact on the operating expenses while CIOs support the adoption due to an anticipation of improved service outcomes.

This paradox is revealed in the resistance of major cloud service providers against the accounting treatments proposed and issued by the Financial Accounting Standards Board (FASB), the US accounting standard setting body. U.S. generally accepted accounting principles (GAAP) require the cost incurred to develop internal-use software to be capitalized (FASB, 2020; ASC 350-40-25-2). In addition, GAAP require costs related to upgrades and enhancements of the existing internal-use software to be capitalized (FASB, 2020; ASC 350-4-25-7). However, when a company switches from owning and maintaining internal-use software to subscribing to cloud-based services, it removes such capitalization opportunities and adds subscription fees as new costs on its income statement. The current accounting standards (ASU 2018-15) stipulate accounting of cloud computing such that the customer in a hosting arrangement must expense all the implementation costs as well as subscription fees if the cloud hosting arrangement does not include a license to internal-use software. In reality, most cloud computing arrangements do not include such a license. Providers such as Google, Salesforce, and 20 other stakeholders objected to the proposal of these standards because such accounting treatment poses a potential threat to the cloud computing providers as expensing cloud-related costs immediately instead of capitalizing them may discourage their cloud customers by instilling fear of reporting increased operating expenses. (FASB Online Comment Letters, 2014)

This study analyzes a sample of advertised early cloud adopters and compares key financial indicators between these adopters and a control group of firms from the same industries over the period from 2005 to 2015, which includes the time before and after the first major wave of cloud computing adoption. The results show that early adopters of cloud computing are generally firms with higher financial performance compared to the average firms. Early adopters are more likely to be successful firms with more resources and perhaps better management. This does not necessarily indicate that the early adoption resulted in specific benefits for the firms. The analysis is complicated by the fact that successful adopters have always been high performers on financial variables over the cloud computing adoption period. Nonetheless, several financial variables stand out to be statistically significant. First, the ratios of depreciation expenses as well as operating expenses to revenues are significantly lower in the adopting firms in most of the years in our sample. This suggests that cloud adopters realize savings in depreciation and improve operational efficiency. Second, the gross margin ratio and the market-to-book ratio are significantly higher in the 
adopting group in most of the years. This implies that investors expect comparably higher earnings growth, potentially due to higher profitability due to the adoption of cloud computing.

The article proceeds as follows. We discuss the construction of our data sample and our empirical methodology in the next section. Presentation of our empirical results comes next. The final section presents conclusions and implications of this study.

\section{DATA AND METHODOLOGY}

We begin our analysis by selecting a sample of firms that adopted of cloud computing early. Successful cloud service adopters are identified through the customer success stories and cases that are published on the web sites of the following major cloud service providers - Amazon (Amazon Web Services), Google Cloud, Microsoft (Azure), IBM, and Salesforce. These companies are the leading U.S. providers in the cloud service market that offer services and products ranging from infrastructure, servers, databases, and applications as a service (Youssef, 2012; Richter, 2020). We identified 107 unique companies that successfully adopted cloud computing solutions from these providers in the period from 2005 to 2015 across various industries. We call these firms successful adopters. The analysis of their four-digit SIC codes reveals that these cloud leaders come from 75 unique industries. Using the Compustat database, we identified the control group by selecting all of the other companies in the industries with the same fourdigit SIC codes as those of the successful adopters. There is an average of 41 firms per industry in the control group. We collected key financial information of the adopters and control firms for the period from 2005 to 2015 from the Compustat database. Table 1 summarizes the number of firms in the sample in each year and presents a comparison of the revenues and assets for the firms included in the sample and the control group in each year.

TABLE 1

COMPARISON BETWEEN CLOUD ADOPTERS AND CONTROL GROUP

\begin{tabular}{|c|c|c|c|c|c|c|}
\hline & \multicolumn{3}{|c|}{ Successful Adopters } & \multicolumn{3}{c|}{ Control Group } \\
\hline Year & $\begin{array}{c}\text { Number } \\
\text { of firms }\end{array}$ & $\begin{array}{c}\text { Mean of } \\
\text { Revenues } \\
\text { (in \$ millions) }\end{array}$ & $\begin{array}{c}\text { Mean of Total } \\
\text { Assets } \\
\text { (in \$ millions) }\end{array}$ & $\begin{array}{c}\text { Number } \\
\text { of firms }\end{array}$ & $\begin{array}{c}\text { Mean of } \\
\text { Revenues } \\
\text { (in \$ millions) }\end{array}$ & $\begin{array}{c}\text { Mean of Total } \\
\text { Assets } \\
\text { (in \$ millions) }\end{array}$ \\
\hline 2005 & 87 & $12,665.76$ & $27,661.91$ & 3314 & $2,910.34$ & $4,535.59$ \\
\hline 2006 & 90 & $13,432.05$ & $28,519.57$ & 3192 & $3,333.88$ & $6,282.10$ \\
\hline 2007 & 90 & $14,799.21$ & $31,798.40$ & 3037 & $3,570.71$ & $6,877.77$ \\
\hline 2008 & 92 & $15,179.14$ & $36,451.01$ & 2954 & $3,657.82$ & $6,405.99$ \\
\hline 2009 & 93 & $14,818.05$ & $36,207.31$ & 2863 & $3,692.29$ & $7,283.52$ \\
\hline 2010 & 96 & $15,640.38$ & $36,852.38$ & 2819 & $3,990.23$ & $7,935.36$ \\
\hline 2011 & 101 & $16,149.55$ & $37,278.47$ & 2813 & $4,384.02$ & $7,880.12$ \\
\hline 2012 & 105 & $16,571.09$ & $38,258.33$ & 2848 & $4,589.99$ & $8,308.07$ \\
\hline 2013 & 106 & $16,298.03$ & $39,232.27$ & 2859 & $4,889.43$ & $8,981.13$ \\
\hline 2014 & 107 & $17,002.17$ & $40,617.89$ & 2841 & $4,824.92$ & $9,295.90$ \\
\hline 2015 & 107 & $16,756.47$ & $39,351.27$ & 2650 & $4,908.94$ & $9,856.04$ \\
\hline
\end{tabular}

Table 1 reveals that the successful adopters are significantly larger companies than the average firms in the same industries based on the comparison of revenues and assets. In our further analysis, we calculate ratios for the financial variables in order to control for the differences in firm size. The key variables for 
our analysis include the ratios of fixed assets to total assets, depreciation expenses to revenues, operating expenses to revenues, market-to-book value ratio, and gross margin ratio. Table 2 describes the definitions of the five variables used in our analysis as well as our predicted relationships for these variables in regard to cloud computing adopters.

In our empirical analysis, we compare these financial ratios between the sample of successful adopters and the control group. After a basic comparison of the means, we employ the Wilcoxon signed rank test to evaluate whether the sample of successful adopters is different from the control group. We use the Wilcoxon test because the variable values in the dataset do not resemble a normal distribution (Bharadwaj, 2000; Chae, Koh, and Prybutok, 2014). The Wilcoxon signed rank test is a nonparametric statistical procedure for comparing two samples that are related when the assumptions for parametric analysis such as normal distributions are not met. This test uses ranked or ordinal data and is a common alternative to the dependent samples t-test when the assumptions for the normal distributions are not met (Corder and Foreman, 2009).

TABLE 2

VARIABLE DESCRIPTIONS

\begin{tabular}{|l|l|l|}
\hline Variable & \multicolumn{1}{|c|}{ Definition } & \multicolumn{1}{c|}{ Predicted relationship } \\
\hline FA/TA & Fixed assets / Total assets & $\begin{array}{l}\text { Adopters have lower FA/TA ratio due to } \\
\text { decreased fixed asset investment. }\end{array}$ \\
\hline DEXP/R & Depreciation expenses / Revenues & $\begin{array}{l}\text { Adopters have lower DEXP/R ratio as } \\
\text { savings in depreciation are observed due to } \\
\text { reduced fixed assets. }\end{array}$ \\
\hline $\mathrm{GM} / \mathrm{R}$ & $\begin{array}{l}\text { Gross Margin Ratio }= \\
\text { (Revenues - Cost of goods sold) / Revenues }\end{array}$ & $\begin{array}{l}\text { Adopters have higher gross margin ratio due } \\
\text { to improved productivity. }\end{array}$ \\
\hline OEXP/R & Operating expenses / Revenues & $\begin{array}{l}\text { Adopters have lower operating expenses due } \\
\text { to increased operational efficiency. }\end{array}$ \\
\hline $\mathrm{MV} / \mathrm{BV}$ & $\begin{array}{l}\text { Market-to-book ratio }= \\
\text { Market value / Book value }\end{array}$ & $\begin{array}{l}\text { Adopters have higher Market-to-book ratio } \\
\text { as investors expect improved performance. }\end{array}$ \\
\hline
\end{tabular}

\section{RESULTS}

Our analysis starts with a look at the key financial variables including the ratios of fixed assets to total assets, depreciation expenses to revenues, operating expenses to revenues, market-to-book value ratio, and the gross margin ratio. Table 3 compares the means of these financial ratios for the successful adopters with those for the control group in a given year. A simple comparison of the means yields several conclusions that are explored more precisely in further analysis. The means for the sample of successful adopters of cloud computing are lower in most years on the ratios of depreciation expenses to revenue and operating expenses to revenue. This is consistent with the predicted relationships for these variables and indicates that such firms realize savings in depreciation and achieve greater operational efficiency. The means for the gross margin ratio and the market-to-book value ratio are higher for the sample group in most of the years. This again is consistent with our predicted relationships and indicates that early adopters generally have higher profitability and higher growth in stock prices. We observe no clear relationship for the ratio of fixed assets to total assets of the firm.

In order to further illustrate the basic relationships in the financial ratios between the sample of the early adopters of cloud computing and the control group firms from the same industries, we present a graphical comparison of the trends in the five financial ratios in Figure 1. This graphical evidence confirms that the ratios of the operating and depreciation expenses to revenues are lower for the successful adopters. These adopters are also more profitable as indicated by the gross margin, even in the period marked by the recession of 2008. The market-to-book ratio for the successful adopters diverges from the rest of the industry after 2008 indicating that the stock prices of these firms have been growing faster as they invested 
in cloud computing. The differences between the groups seen in Figure 1 are remarkably consistent and are observed even in the years around the 2008 financial crisis and recession. The next step in our analysis is to test the findings statistically using the Wilcoxon signed rank test.

The summary of the results from the Wilcoxon signed rank test is presented in Table 4 . This evidence confirms that the values in the sample group are lower than the values in the control group for the ratios of the operating and depreciation expenses to revenues. This result is significant at the 1 percent level for the operating expenses ratio in every year. The result is significant at the 5 percent level for most years after 2009 for the depreciation expenses ratio. We also find that the ratio of fixed assets to total assets is lower in the sample group than in the control group in all of the years of the sample. However, this result is not statistically significant.

TABLE 3

MEANS OF VARIABLES FOR ADOPTERS SAMPLE AND CONTROL GROUP

\begin{tabular}{|c|c|c|c|c|c|c|c|c|c|c|}
\hline \multirow[b]{2}{*}{ Year } & \multicolumn{2}{|c|}{ FA/TA } & \multicolumn{2}{|c|}{ DEXP/R } & \multicolumn{2}{|c|}{ GM/R } & \multicolumn{2}{|c|}{ OEXP/R } & \multicolumn{2}{|c|}{ MV/BV } \\
\hline & $\begin{array}{l}\frac{n}{0} \\
\stackrel{0}{0} \\
\frac{0}{0} \\
\frac{0}{4}\end{array}$ & $\begin{array}{l}\overline{0} \\
\stackrel{\Xi}{0} \\
\dot{0}\end{array}$ & $\begin{array}{l}\frac{n}{0} \\
\stackrel{0}{0} \\
\frac{0}{0} \\
\frac{0}{4}\end{array}$ & $\begin{array}{l}\overline{0} \\
\stackrel{\Xi}{0} \\
0\end{array}$ & $\begin{array}{l}\frac{n}{0} \\
\frac{0}{2} \\
\frac{0}{2}\end{array}$ & 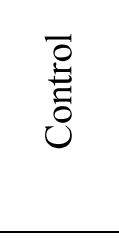 & $\begin{array}{l}\frac{n}{0} \\
\frac{0}{0} \\
\frac{0}{0}\end{array}$ & \begin{tabular}{l}
$\overline{0}$ \\
\multirow{0}{0}{} \\
0
\end{tabular} & $\begin{array}{l}\frac{n}{0} \\
\frac{0}{2} \\
\frac{0}{0}\end{array}$ & $\begin{array}{l}\overrightarrow{0} \\
\text { : } \\
\text { Ȯ }\end{array}$ \\
\hline 2005 & 0.444 & 0.451 & 0.058 & 0.065 & 0.368 & -0.199 & 0.866 & 1.057 & 4.674 & 4.394 \\
\hline 2006 & 0.441 & 0.436 & 0.057 & 0.060 & 0.355 & 0.320 & 0.894 & 1.040 & 4.183 & 4.389 \\
\hline 2007 & 0.435 & 0.413 & 0.054 & 0.059 & 0.019 & -0.237 & 0.856 & 1.153 & 4.512 & 4.235 \\
\hline 2008 & 0.451 & 0.427 & 0.059 & 0.059 & 0.372 & 0.283 & 0.998 & 1.078 & 3.207 & 1.064 \\
\hline 2009 & 0.444 & 0.455 & 0.060 & 0.067 & 0.391 & 0.322 & 0.872 & 1.058 & 7.309 & 3.948 \\
\hline 2010 & 0.427 & 0.442 & 0.052 & 0.065 & 0.419 & 0.231 & 0.826 & 1.102 & 1.124 & 1.376 \\
\hline 2011 & 0.428 & 0.434 & 0.057 & 0.060 & 0.410 & 0.296 & 0.852 & 1.046 & 2.201 & 3.205 \\
\hline 2012 & 0.423 & 0.464 & 0.054 & 0.059 & 0.429 & 0.350 & 0.827 & 0.987 & 3.582 & 1.683 \\
\hline 2013 & 0.430 & 0.427 & 0.053 & 0.066 & 0.431 & 0.322 & 0.831 & 1.045 & 3.729 & 1.896 \\
\hline 2014 & 0.424 & 0.406 & 0.056 & 0.064 & 0.452 & 0.343 & 0.983 & 1.051 & 5.391 & -0.953 \\
\hline 2015 & 0.420 & 0.417 & 0.055 & 0.065 & 0.450 & 0.312 & 0.858 & 1.078 & 0.131 & 2.646 \\
\hline
\end{tabular}

The results further indicate that the values in the sample group of cloud adopters are higher than in the control group for the ratios of gross margin and market-to-book value. This result is significant in seven of the years for the gross margin ratio and in six of the years for the market-to-book value ratio. The significant results are indicated in bold in Table 4.

The findings of the statistical analysis are generally consistent with the predicted relationships specified in Table 2 and indicate that adoption of cloud computing is associated with savings in depreciation expenses, improved operational efficiency, higher profitability as measured by the gross margin, and generally higher market-to-book ratio. More of these results are significant in the later years of the sample period as the benefits of cloud computing are realized by the adopting firms.

\section{DISCUSSION AND CONCLUSION}

In this study, we explore the impact of cloud computing service adoption on the various metrics of financial performance at the adopting firms. Cloud computing investment is expanding however disagreements abound among the finance and accounting professionals regarding the costs and benefits of the adoption (Goldstein, 2020a; 2020b). Cloud service providers claim that the primary benefits of using such services are reduced cost in maintaining IT staff and computing devices and facilities, as well as 
associated depreciation cost, and increased profitability due to the improved operational efficiency and system availability. In contrast, accounting and finance professionals warn about potential negative impact on key financial reporting metrics including increased operating expenses and decreased EBITDA due to the newly added subscription fees (Goasduff, 2015).

We analyze a unique sample of reported early cloud service adopters and compare their financial reporting metrics of interest to those of the control group constructed from average firms in the same industries as the adopters over the period from 2005 to 2015. Our study has two major findings. First, we find that early adopters exhibit lower operating expenses as well as lower depreciation expenses than the control group. The result for depreciation expenses becomes statistically significant after 2009. This timing is consistent with the wider roll-out of cloud computing services. Second, early adopters also exhibit higher gross margin and market-to-book ratios implying that investors expect comparably higher earnings growth, potentially due to the expected efficiencies achieved by using cloud computing.

\section{FIGURE 1 \\ COMPARISON OF MEAN VALUES BETWEEN SUCCESSFUL ADOPTERS AND CONTROL GROUP BY YEAR}

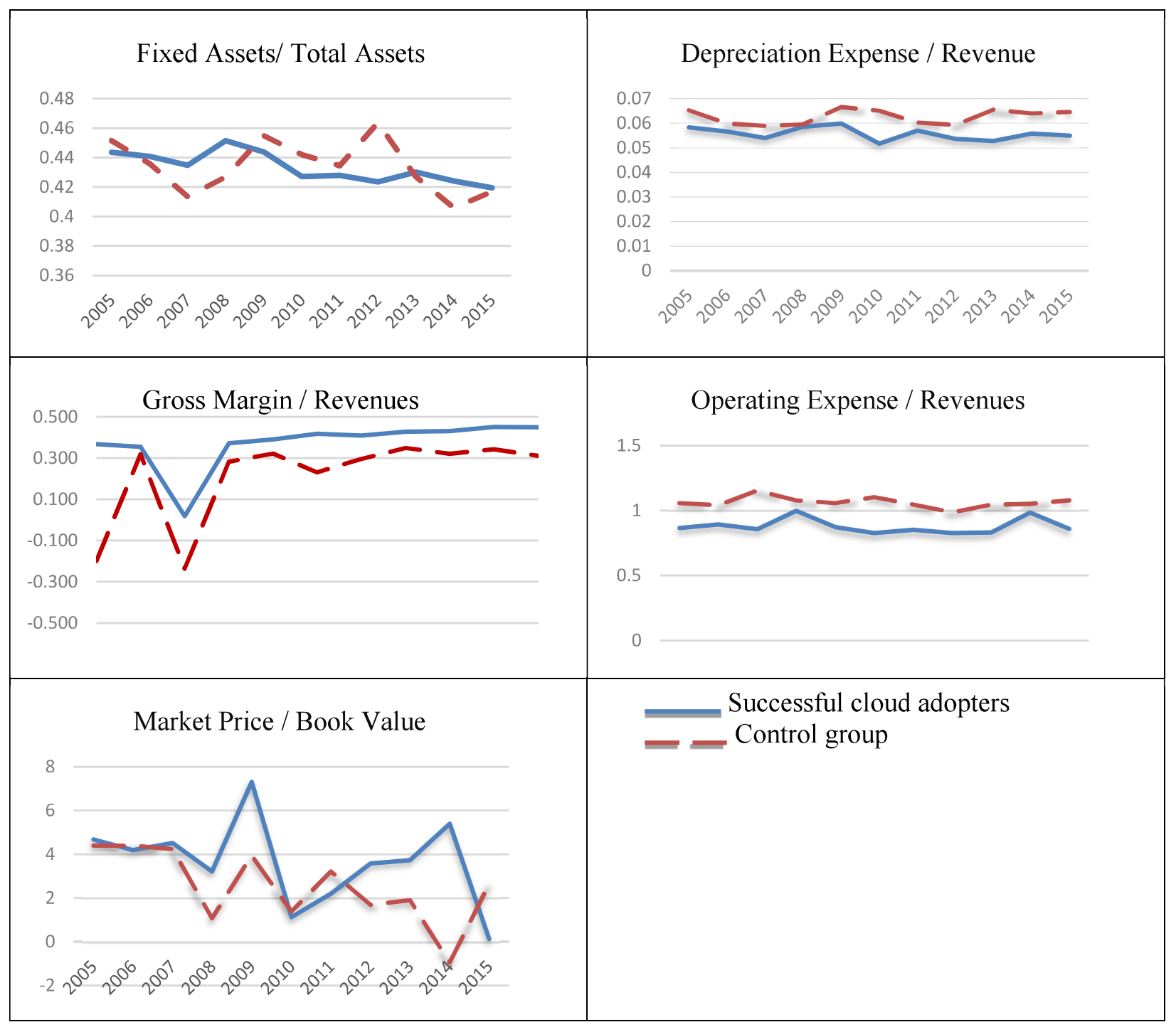


We analyze a unique sample of reported early cloud service adopters and compare their financial reporting metrics of interest to those of the control group constructed from average firms in the same industries as the adopters over the period from 2005 to 2015. Our study has two major findings. First, we find that early adopters exhibit lower operating expenses as well as lower depreciation expenses than the control group. The result for depreciation expenses becomes statistically significant after 2009. This timing is consistent with the wider roll-out of cloud computing services. Second, early adopters also exhibit higher gross margin and market-to-book ratios implying that investors expect comparably higher earnings growth, potentially due to the expected efficiencies achieved by using cloud computing.

Research on information technology adoption identified several conceptual models for the adoption decisions including the technology acceptance model (TAM) and the unified theory of acceptance and use of technology (Venkatesh et al., 2003, 2012; Gangwar et al., 2014) as well as specific factors that affect technology adoption (Kamal, 2006; Kim et al., 2008; Ghezzi et al., 2013; Chulkov, 2017). While this literature identified financial factors as important, it did not present significant empirical evidence on the financial impact of technology adoption. This is one area in which our study provides a contribution.

TABLE 4

RESULTS OF WILCOXON SIGNED RANK TEST

\begin{tabular}{|c|c|c|c|c|c|c|}
\hline$\stackrel{\Xi}{ \pm}$ & & FA/TA & DEXP/R & GM/R & OEXP/R & MP/BV \\
\hline \multirow{2}{*}{ 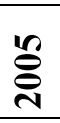 } & Z & $-.834^{b}$ & $-1.368^{b}$ & $-7.084^{\mathrm{a}}$ & $-4.610^{b}$ & $-1.224^{\mathrm{a}}$ \\
\hline & $\mathrm{P}$ & 0.404 & 0.171 & $0.000 * * *$ & $0.000 * * *$ & 0.221 \\
\hline \multirow{2}{*}{ ¿̊ํㅇ } & $\mathrm{Z}$ & $-.764^{b}$ & $-.990^{b}$ & $-.643^{a}$ & $-4.188^{b}$ & $-1.904^{\mathrm{a}}$ \\
\hline & $\mathrm{P}$ & 0.445 & 0.322 & 0.520 & $\mathbf{0 . 0 0 0 * * *}$ & $0.057^{*}$ \\
\hline \multirow{2}{*}{ 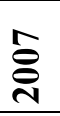 } & $\mathrm{Z}$ & $-.006^{b}$ & $-1.127^{b}$ & $-4.206^{\mathrm{a}}$ & $-5.019^{b}$ & $-.529^{a}$ \\
\hline & $\mathrm{P}$ & 0.995 & 0.260 & $0.000 * * *$ & $0.000 * * *$ & 0.597 \\
\hline \multirow{2}{*}{$\stackrel{\infty}{\stackrel{\overbrace{}}{ٍ ̆}}$} & $\mathrm{Z}$ & $-.284^{b}$ & $-1.015^{b}$ & $-1.554^{\mathrm{a}}$ & $-4.731^{b}$ & $-1.665^{\mathrm{a}}$ \\
\hline & $\mathrm{P}$ & 0.776 & 0.310 & 0.120 & $\mathbf{0 . 0 0 0 * * *}$ & 0.096 * \\
\hline \multirow{2}{*}{ 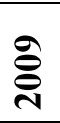 } & $\mathrm{Z}$ & $-1.448^{b}$ & $-1.575^{b}$ & $-1.516^{\mathrm{a}}$ & $-4.302^{b}$ & $-1.288^{\mathrm{a}}$ \\
\hline & $\mathrm{P}$ & 0.148 & 0.115 & 0.130 & $0.000 * * *$ & 0.198 \\
\hline \multirow{2}{*}{ 을 } & $\mathrm{Z}$ & $-1.161^{b}$ & $-2.765^{b}$ & $-2.203^{\mathrm{a}}$ & $-4.690^{b}$ & $-1.713^{\mathrm{a}}$ \\
\hline & $\mathrm{P}$ & 0.246 & $0.006 * *$ & $0.028 * *$ & $0.000 * * *$ & $0.087^{*}$ \\
\hline \multirow{2}{*}{$\overline{\vec{\nu}}$} & Z & $-1.031^{b}$ & $-1.132^{b}$ & $-2.022^{\mathrm{a}}$ & $-4.293^{b}$ & $-1.109^{a}$ \\
\hline & $\mathrm{P}$ & 0.302 & 0.257 & 0.043 ** & $0.000 * * *$ & 0.267 \\
\hline \multirow{2}{*}{ 글 } & $\mathrm{Z}$ & $-1.611^{b}$ & $-1.823^{b}$ & $-1.841^{\mathrm{a}}$ & $-4.480^{b}$ & $-2.233^{\mathrm{a}}$ \\
\hline & $\mathrm{P}$ & 0.107 & $0.068 *$ & $0.066^{*}$ & $0.000 * * *$ & $0.026^{* *}$ \\
\hline \multirow{2}{*}{$\stackrel{m}{\stackrel{\sim}{\sim}}$} & $\mathrm{Z}$ & $-1.094^{b}$ & $-1.982^{b}$ & $-1.809^{a}$ & $-4.541^{b}$ & $-1.755^{\mathrm{a}}$ \\
\hline & $\mathrm{P}$ & 0.274 & $0.047 * *$ & $0.071^{*}$ & $0.000 * * *$ & 0.079* \\
\hline \multirow{2}{*}{$\underset{\text { ¿ }}{ \pm}$} & $\mathrm{Z}$ & $-.422^{b}$ & $-1.271^{b}$ & $-1.349^{a}$ & $-3.716^{b}$ & $-2.347^{\mathrm{a}}$ \\
\hline & $\mathrm{P}$ & 0.673 & 0.204 & 0.177 & $0.000 * * *$ & $0.019 * *$ \\
\hline \multirow{2}{*}{$\frac{n}{\stackrel{n}{~}}$} & $\mathrm{Z}$ & $-.673^{b}$ & $-1.993^{b}$ & $-2.080^{\mathrm{a}}$ & $-4.345^{b}$ & $-1.565^{\mathrm{a}}$ \\
\hline & $\mathrm{P}$ & 0.501 & $0.046^{* *}$ & $0.037^{* *}$ & $0.000 * * *$ & 0.117 \\
\hline
\end{tabular}

$* * * 1 \%$ level, ** $5 \%$ level, * $10 \%$ level.

a: sample value $>$ control value, ${ }^{\text {b: }}$ sample value $<$ control value 
The empirical results show that cloud computing adopters are generally firms with higher financial performance than control firms over the entire sample period. This does not necessarily indicate that the early adoption of cloud computing resulted in specific benefits for these firms. There is potential for endogeneity in this relationship which makes this analysis difficult as the successful adopters have always been high performers on financial variables over the cloud computing adoption period. Specific tests for endogeneity remain an area for further research.

Our results for the market-to-book ratio imply that firms advertising investments in cloud computing are associated with increased stock prices. These firm may in fact exploit emerging technologies and influence investors with technology buzzwords. Popular press evidence suggests that some companies merely added words such as "blockchain", the technology behind cryptocurrencies, to their names and their stock prices soared (Cheng, 2017; Pham, 2017). Small sample event studies indicate that announcements of cloud computing adoption provide positive returns for the firm's stock (Son et al., 2014; Nicholas-Donald et al., 2018). Our finding concurs with such evidence-embracing the emerging technology trend may result in an increased stock price.

Evaluating the financial impact of cloud computing remains a complex task. Our results focus on a sample of successful early adopters and identify the variables that are significantly different in the adopting group. These findings provide an initial groundwork for researchers who attempt to further study the value of cloud computing for a business. Furthermore, these results can be used as a reference for practitioners striving to understand how the emerging mode of technology delivery affects the accounting variables and contributes to a firm's performance.

\section{REFERENCES}

Bharadwaj, A. (2000). A Resource-Based Perspective on Information Technology Capability and Firm Performance: An Empirical Investigation. MIS Quarterly, 24(1), 169-196.

Chae, H., Koh, C., \& Prybutok, V. (2014). Information Technology Capability and Firm Performance: Contradictory Findings and Their Possible Causes. MIS Quarterly, 38(1), 305-326.

Cheng, E. (2017, December 21). \$24 million iced tea company says it's pivoting to the blockchain, and its stock jumps 200 percent. $C N B C$. Retrieved from http://cnb.cx/2BTNRrl

Chulkov, D. (2017). On the role of switching costs and decision reversibility in information technology adoption and investment. Journal of Information Systems and Technology Management, 14(3), 309-321.

Conner, B. (2016, September) Can cloud computing impact your EBITDA? Healthcare Financial Management, pp. 36-38.

Corder, G.W., \& Foreman, D.I. (2009). Nonparametric Statistics for Non-statisticians: A Step-by-Step Approach, New York, NY: Wiley.

FASB (2020). Accounting Standards Update (ASU) No. 2018-15. Accounting standards codification. Retrieved from http://asc.fasb.org

FASB Online Comment Letters. (2014). Project: 2014-230 Customer's Accounting for Fees Paid in a Cloud Computing Arrangement. Retrieved from https://www.fasb.org/jsp/FASB/CommentLetterPage

Furht, B., \& Escalante, A. (2010). Handbook of cloud computing (Vol. 3). New York, NY: Springer.

Gangwar, H., Date, H., \& Raoot, A.D. (2014). Review on IT adoption: insights from recent technologies, Journal of Enterprise Information Management, 27, 488-502.

Ghezzi, A., Rangone, A., \& Balocco, R. (2013). Technology diffusion theory revisited: a regulation, environment, strategy, technology model for technology activation analysis of mobile ICT. Technology Analysis \& Strategic Management, 25(10), 1223-1249.

Goasduff, L. (2015) The Financial Case for Moving to the Cloud. Gartner Research, Retrieved from: https://www.gartner.com/smarterwithgartner/the-financial-case-for-moving-to-the-cloud

Goldstein, E. (2020a, January) Accounting for cloud computing: What you need to know. Journal of Accountancy.

234 Journal of Applied Business and Economics Vol. 23(1) 2021 
Goldstein, E. (2020b, July) FASB's new cloud computing standard reduces complexity. Journal of Accountancy.

Höfer, C.N., \& Karagiannis, G. (2011) Cloud computing services: taxonomy and comparison. Journal of Internet Services and Applications, 2(2), 81-94.

Kamal, M. (2006). IT innovation adoption in the government sector: identifying the critical success factors, Journal of Enterprise Information Management, 19, 192 - 222.

Kim, J.Y., Altinkemer, K., \& Chulkov, D. (2008). Should the firm promote older generation products? Optimal strategy for rapidly improving technology. Journal of Academy of Business and Economics, 8(2), 100-113.

Nicholas-Donald, A., Mahmood, M.A., \& Trevino, L.L. (2018). Does adoption of cloud computing matter? The economic worth of cloud computing implementation. International Journal of Information Systems and Management, 1(4), 328-342.

Novais, L., Maqueira, J.M., \& Ortiz-Bas, Á. (2019). A systematic literature review of cloud computing use in supply chain integration. Computers \& Industrial Engineering, 129, 296-314.

Pham, L. (2017, October 27). This Company Added the Word 'Blockchain' to Its Name and Saw Its Shares Surge 394 percent, Bloomberg. Retrieved from https://www.bloomberg.com/news/articles/2017-10-27/what-s-in-a-name-u-k-stock-surges-394on-blockchain-rebrand

Richter, F. (2020). Amazon Leads $\$ 100$ Billion Cloud Market. Statista. Retrieved from: https://www.statista.com/chart/18819/worldwide-market-share-of-leading-cloud-infrastructureservice-providers/

Son, I., Lee, D., Lee, J., \& Chang, Y. (2014). Market perception on cloud computing initiatives in organizations: An extended resource-based view. Information \& Management, 51(6), 653-669.

Venkatesh, V., Morris, M.G., Davis, G.B., \& Davis, F. (2003). User Acceptance of Information Technology: Toward a Unified View, MIS Quarterly, 27(3), 425-478

Venkatesh, V., Thong, J.Y., \& Xu, X. (2012). Consumer acceptance and use of information technology: extending the unified theory of acceptance and use of technology. MIS Quarterly, 36(1), 157-178.

Yang, C., Huang, Q., Li, Z., Liu, K., \& Hu, F. (2017). Big Data and cloud computing: innovation opportunities and challenges. International Journal of Digital Earth, 10(1), 13-53.

Youssef, A.E. (2012). Exploring cloud computing services and applications. Journal of Emerging Trends in Computing and Information Sciences, 3(6), 838-847. 